\title{
АНАЛИЗ ПОДХОДОВ К ИЗУЧЕНИЮ ФЕНОМЕНА ЭКЗИСТЕНЦИАЛЬНОГО ВЫБОРА
}

\section{THE ANALYSIS OF APPROACHES TO STUDYING EXISTENTIAL CHOICE PHENOMENON}

\section{Z. Myasnikova}

Summary: The analysis of the authors' various approaches to understanding existential choice category is represented in this article. Also the necessity of studying this phenomenon is proved.

Keywords: existential choice, valuable orientations, life choice, personal growth, life style, indeterminacy.
$\mathrm{B}$ психологии экзистенциального направления принято считать, что развитие личности определяется ее выбором, путем диалога с внешним и внутренним миром личность создает сама себя, проходит этапы своего развития. В связи с развитием современной цивилизации происходит обострение фундаментальных проблем человеческого существования. Этим обусловлена потребность в изучении взаимоотношений человека с миром, смысла жизни, факторов утраты смысла, а также условий и механизмов его восстановления. Так, Дружинин В.Н. определял экзистенциальную психологию как науку «о том, как человеческая судьба зависит от отношения человека к жизни и смерти, «о разнообразии и типологии человеческих жизней», «о человеческом сознании и субъективной реальности, которая является отражением жизни в образе индивидуального жизненного пути» [2].

Ярчайшими примерами исследователей, занимавшихся проблемой экзистенциального выбора, являются Эрих Фромм, Ролло Мэй, Виктор Франкл. Также большой вклад в развитие теории экзистенциального выбора внесли Василюк Ф.Е., Наумова Н.Ф., Петровский B.А., Мадди С.Р. В рамках настоящей статьи планируется рассмотреть подходы данных авторов к изучению экзистенциального выбора. На наш взгляд, значимость и практическая ценность изучения подходов к теории экзистенциального выбора очевидна для психотерапевтической, трениинговой и консультативной работы специалиста. поскольку в реальности путем применения простых методик в ситуациях опустошенности и обреченности от бытия позволяет личности найти новые смыслы и выборы, выйти из позиции жертвы.

Поддерживая идеи философов-экзистенциалистов относительно выбора, данные авторы позиционируют выбор как проявление фундаментальной человеческой свободы, мужества и реализацию смыслов и ценностных ориентаций личности. В своих взглядах они уделяют внимание самоопределению личности, ее активной позиции и происходящих в ней изменениях вследствие совершения акта выбора. Авторы понимают выбор как процесс, наиболее значимым компонентом которого является акт принятия на себя ответственности за последствия своего решения, при этом колоссальное значение придается тому, насколько обдуманно, ответственно или, напротив, импульсивно и спонтанно совершается выбор. При этом не берется во внимание конкретный результат и то, произошло ли принятие и осознание личностью совершенного выбора. Другими словами, под выбором следует понимать не единичное явление, акт, а совокупность жизненных выборов, которые и формируют индивидуальную стратегию поведения личности в ситуации неопределенности.

В соответствии с теорией С. Мадди, существуют две кардинально различающиеся стратегии - выбор прошлого и выбор будущего - на основании которых и происходит формирование жизненного стиля личности. Так, например, человек, выбирающий прошлое, лишает себя возможности саморазвития, но при этом сохраняет спокойствие, так как ему не нужно рисковать, он руководствуется опытом прошлого, исход ситуации для него, скорее всего, известен. Человек, выбирающий будущее, напротив, подвержен сомнениям и тревогам перед неопределенностью, однако именно так и происходит качественный личностный рост.

С данной концепцией схожи идеи отечественного психолога Н.А. Логиновой, которая занималась иссле- 
дованием выборов человека на протяжении жизни во временной перспективе его развития. Автор убеждена, что «связь психологического прошлого с настоящим и будущим выступает в каждом случае жизненного выбора» [3]. Кроме того, она подчеркивает влияние структуры индивидуальности личности и работы ее сознания на экзистенциальный выбор и жизнедеятельность личности в целом.

Признавая свободу человека, А. Лэнгле отмечает, что «при многократном повторении определенных поступков какие-то жизненные пути становятся привычными, а другие зарастают» [4]. По мнению автора, зависимость от ситуации и автоматизм, с которым личность совершает выбор, сужают ее свободу.

Интересным для исследования представляется подход Василюка Ф.Е. к изучению экзистенциального выбора. Автор разрабатывает представление о жизненных мирах и описывает их внешний и внутренний аспекты, которые отражают степень легкости или трудности немедленного и полного удовлетворения возникшей потребности и степень простоты или сложности потребностей личности [1]. Согласно его теории, данные категории служат основой для выделения «четырех типов жизненных миров: инфантильный (внутренне простой и внешне легкий), реалистический (внутренне простой и внешне трудный), ценностный (внутренне сложный и внешне легкий) и творческий (внутренне сложный и внешне трудный)» [1].

С точки зрения Василюка Ф.Е., ввиду несложной структуры внутренней простоты жизни, наличия у субъекта единственной потребности (жизненного отношения) или целого ряда жизненных отношений, неперекрещивающихся между собой, выбор в качестве предпочтения одной из имеющихся альтернатив невозможен. Кроме того, выбор также не может базироваться на основе принципиального сравнения альтернатив изза постоянно возникающих внешних затруднений.

Подлинный выбор, по мнению Василюка Ф.Е., возможен только в ценностном мире. Это обусловлено отсутствием со стороны внешнего мира препятствий для выполнения намерений личности, при этом конфликтующие между собой жизненные отношения сопоставляются сами по себе. Данная система является «мотивационно-смысловым ядром личности» [1]. Основой для выбора служит ценность, устойчивая, общечеловеческая, которая выполняет смыслообразующую и смыслоразличающую функции, при этом ценность подвержена произвольным изменениям со стороны личности.

Автор убежден, что во внешне легком мире любая актуализировавшаяся у субъекта выбора потребность воплощается в полной мере, мгновенно и окончательно, что несет в себе оттенок трагичности. В соответствии с идеями автора, этапами подобного ценностного выбора для личности являются следующие:

1. отвлечение от трудности мира при одновременном удержании его сложности;

2. актуализация глубинных ценностей;

3. оценка альтернатив;

4. жертва.

Последний этап - жертва - связан с осознанием необратимости и «экзистенциальной ценности сделанного выбора».

Взгляды Василюка Ф.Е. находят отражение в теории Папуша М., согласно которой человек в ситуации экзистенциального выбора оказывается в точке пересечения двух или нескольких несогласованных действительностей, в каждой из которых он имеет определенный способ поведения, что, в свою очередь, не требует от него принятия решения. Таким образом, ситуация выбора существует в том случае, когда личность сама удерживает пересечение действительностей. Следовательно, выбор и необходимость его осуществить уже существуют, а возможности выбора у личности еще нет, поскольку она не может исключить из числа имеющихся действительностей ни одну.

Поддерживая идеи Ф. Перлза и Э. Берна, Папуш М. приходит к выводу о том, что выбор является «виртуальной ситуацией, поддерживаемой личностью, поверх субличностей выбирающей себя, поскольку в прочих «гомогенных» ситуациях те или иные субличности справляются сами» [7].

Согласно концепции Петровского В.А., личность, осуществляющая выбор, представлена как «единомножие субъектов»: Родителя, Взрослого и Ребенка [8]. Автор руководствовался идеей описания, объяснения и предсказания поведения личности в ситуации жизненной неопределенности. Петровским В.А. был введен термин «виртуальной состоятельности» личности, посредством которого возможно обозначить ее нижний и верхний пределы, на что может рассчитывать личность в тех или иных обстоятельствах, благоприятных или нет. Данные обстоятельства, в свою очередь, зависят от стечения импульсов, которые производятся указанными выше категориями (Родитель, Взрослый, Ребенок).

Колоссальное значение в своей теории Петровский В.А. придает опыту прошлого, сосредоточенному в Ребенке, значению этого опыта для процесса бессознательной интерпретации окружающей действительности и способности к совершению экзистенциального выбора, поскольку виртуальная состоятельность не может быть ниже ресурсов, предоставляемых Ребенком. Автор отмечает, что прекращение либо отсутствие поддержки 
со стороны Родителя, которые «выражаются в виде наставительных импульсов, а также заинтересованность Взрослого, который служит в качестве разумной части личности, приводят к ее повышению. Другими словами, отсутствие полного контроля над ситуацией выбора со стороны инстанции «Родитель» позволяет инстанции «Ребенок» повысить свою состоятельность, развивать зрелость и способность к осуществлению выбора. Согласно идее Петровского, «внутренняя состоятельность личности, осуществляющей экзистенциальный выбор, должна еще быть испытана миром» [8]. Данная позиция понимается нами следующим образом: только зрелая личность с приобретенным в процессе своей жизни опытом, положительным или отрицательным, способна рационально прожить и принять все этапы, предшествующие экзистенциальному выбору.

Более лаконичен и понятен подход Мадди С.Р. к феномену экзистенциального выбора. По его мнению, подлинный выбор выступает как шаг, содержание и направленность которого «наделяют жизнь уникальным смыслом, в соответствии с чем выделяются две различающиеся стратегии выбора человека, являющиеся основой его жизненного стиля: выбор прошлого и выбор будущего» [5].

Согласно его теории, постоянный выбор личностью прошлого, привычных способов реагирования на различные сложности, уготованные жизнью, свидетельствует о стремлении личности к безопасности и комфорту. Однако подобный склад вещей со временем приводит личность к «информационному вакууму», в результате которого определенность и однозначность отношений личности с миром, в которых нет ни намека на какиелибо изменения, приводит к жизненному застою, скуке, ощущению собственного бессилия, растрачиванию моральных энергетических ресурсов и, как следствие, к переживанию вины, связанной с упущенными возможностями, и осознанию бессмысленности собственного существования.

В основе такого жизненного стиля, по мнению Мадди С.Р., заложен конформизм, уязвимость перед стрессогенными обстоятельствами, страх и неспособность «держать удар». Личности, придерживающиеся подобного жизненного стиля, подвержены таким негативно заряженным «крайностям» как авантюризм, нигилизм и вегетативность.

Выбирая будущее, личность находится в процессе постоянного саморазвития, накопления опыта, расширения границ личностного потенциала и своего представления о мире, в результате чего происходит формирование жизнестойкости, отваги. Под жизнестойкостью в рамках настоящей концепции Мадди С.Р. понимал «ядро личности, верность человека самому себе и опору на собственные силы в тяжелые моменты, позволяющую уменьшить онтологическую тревогу, возникающую из-за той непредсказуемости, неизвестности, с которой сталкивается личность в процессе выбора в пользу будущего» [5].

Качество жизнестойкости формируется в процессе контроля ситуации личностью, борьбы со стрессогенными обстоятельствами и готовностью непрерывно учиться на собственном опыте. Формирование и развитие индивидуализма, полноценного продуктивного взаимодействия человека с другими людьми, основанного на взаимовыручке, помощи, способности поддержать, а также забота о собственном здоровье как о бесценном даре, являются следствием выбора личности в пользу будущего.

Занимаясь проблемой экзистенциального выбора, автор сформулировал основные задачи экзистенциально-ориентированной психотерапии, вытекающие из его концепции:

- воспитание индивидуализации в человеке, облегчение для него регулярного выбора будущего;

- формирование жизнестойкости как важного качества для управления тревогой.

На наш взгляд, в стремительно меняющемся, прогрессивном мире, в ситуациях, когда необходимо незамедлительно принять решение и осуществить выбор, одной из приоритетных характеристик личности должна выступать ее способность принимать неопределенность будущего и риск как нечто естественное, обыденное.

Анализируя особенности экзистенциального выбора, Лэнгле А. в своем подходе ключевую роль отводит процессу воли. С точки зрения автора, фундаментальной базой для воли являются «возможности личности, затронутость некоторой ценностью, совесть и смысл» [4]. Согласно данной теории, внутреннее «да» по отношению к определенной ценности является решением личности, и оно может быть целостным и свободным только в случае сосредоточенности в воле ее четырех компонентов: «я могу», «мне нравится», «я имею право» и «я должен». Если данное условие не соблюдено, решение переживается личностью как принуждение, в котором не может быть свободы и, соответственно, выбора. Образно говоря, сам акт воли подобен пружине между запросом ситуации и действием человека в ответ на этот запрос.

Очень логично и последовательно Лэнгле А. разложил процесс воли, входящий в структуру экзистенциального выбора, на этапы. В соответствии с этим, на первом этапе личность испытывает чувство затронутости ценностью, которое сменяется взвешиванием ценностей (с точки зрения рациональности и эмоций), после чего принимается решение, которое еще Кьеркегор С. опи- 
сал как «прыжок личности к себе», благодаря которому освобождаются силы, потенциал, личность устремляется навстречу выбранной ценности, испытывая при этом внутреннюю ясность и очевидность, что выбранная ею ценность будет реализована. В процессе воли наблюдаются интересные трансформации, затрагивающие личность: наполненность энергией, концентрированность, чувство персональной свободы, чувство облегчения в ответ на потребности личности делать то, что именно она хочет делать вместо реализации навязанного. На последнем этапе воли происходит действие, личности предоставляется решение, и она чувствует, что готова отвечать за свой выбор.

Кроме того, автор подхода отмечал, что «принимаемое в процессе волевого акта решение не является и не должно восприниматься как некий идеал; это то, что на данный момент является для человека приемлемым» [4]. В соответствии с этим воля является связующим компонентом между личностным идеалом и реальной ситуацией, воля личности свидетельствует о том, что при сложившихся обстоятельствах человек предстает именно таким, и решение принимает его «Я».

Не менее интересным для исследования феномена экзистенциального выбора представляется подход Наумовой Н.Ф., согласно которому выделяются три основные стратегии целеполагания: экстремистская (стратегия спонтанного, иррационального выбора, ведущая к формированию гибкости человека, то есть отсутствию устойчивых качеств его личности), принятие решений (редукция целеполагания, сведения деятельности к автоматизмам) и стратегия свободного выбора. В соответствии с теорией автора, необходимым условием свободного выбора является обеспеченность индивида «потребностями, ценностями, логиками, ресурсами для построения альтернатив выбора и готовности к наибольшему числу вариантов событий» [6]. Следует отметить, что данные параметры возникают у личности, по мнению автора, вынужденно, в процессе осуществления личностью выбора и «сравнения несравнимого по определению», другими словами, осуществления нелогичных, необъединяемых между собой операций.

Стратегия свободного выбора делает сложным взаимодействие личности с окружающей ее действительностью, «делая адаптивное, реактивное поведение невозможным» [6].

В рамках своего подхода Наумова Н.Ф. выделяет такие принципы свободного выбора как:

- альтернативность индивидуальной жизни (внутренняя готовность к осуществлению любой выбранной альтернативы);

- антиномичность (существование логически несовместимых предположений о собственном суще- ствовании, обусловленных двойственностью природы человека);

- неопределенность (неопределенность связи между системой ценностей и возможностями индивида, которые позволяют ему конструировать новые альтернативы выбора);

- случайность (невозможность обоснования выбора в рамках известных критериев);

- время (свободное упорядочивание и трактовка как объективного, так и субъективного времени);

- непосредственное социальное взаимодействие индивида [6].

Анализ подходов к изучению экзистенциального выбора в рамках настоящей статьи позволил нам определить основные принципы и идеи исследуемого феномена. Так, свободная воля личности помогает ему находиться в постоянном развитии, избегая регресса. Природа же личности такова, что она постоянно нуждается в самораскрытии и непрерывном развитии своего потенциала. При этом, личность обладает свободой, волей и возможностью выбора в рамках своих ценностных ориентаций.

Опираясь на высказывание Франкла В. относительно того, что «у каждого времени свои неврозы - и каждому времени требуется своя психотерапия», можно утверждать, что перемены, которые происходят в социальной реальности, изменяют отношения человека с окружающим миром, его взгляды и направления, устраняя одни проблемы и порождая новые. Так, экзистенциальный подход в изучении проблемы выбора в психологии является важным этапом выхода психологической науки на новый уровень выявления и описания проблем личности, ее взаимоотношений с окружающим миром. Потребность в новом уровне описания человеческих проблем обусловлена тем, что традиционная психология не способна в полной мере осветить некоторые феномены, которые выходят за пределы традиционно заданных рамок, опираясь на психологические и ситуационные характеристики. В этой связи совершенно справедливо, что экзистенциальный подход в психологии выбора возникает в качестве ответа на современные кризисы и потребности современного общества.

Так, изучение экзистенциального выбора позволит усовершенствовать психотерапевтические практики, направленные на решение жизненных задач, которые современная реальность ставит перед человеком. По мере становления и развития практической психологии и психологической практики появляются потребности решения все более сложных задач, которые заключаются в помощи человеку при решении проблем адаптации и самореализации, а также - более комплексных задач решения экзистенциальных проблем, поиска смысла своего существования. 


\section{ЛИТЕРАТУРА}

1. Василюк Ф.Е. Психотехника выбора // Психология с человеческим лицом: Гуманистическая перспектива в постсоветской психологии / под ред. Д.А. Леонтьева. - М.: Смысл, 1997. - 330 с.

2. Дружинин В.Н. Варианты жизни: очерки экзистенциальной психологии. М.: ПЕР СЭ; СПб.: ИМАТОН-М, 2000. - 214 с.

3. Логинова Н.А. Жизненный выбор личности // Психобиографический метод исследования и коррекции личности: Учебное пособие. - Алматы: Казак. Университет, 2001. - 172 с.

4. Лэнгле А. Экзистенциально-аналитическая теория личности. - М.: Генезис, 2005. - 159 с.

5. Мадди С. Смыслообразование в процессах принятия решения // Психологический журнал. - 2005. - Т. 26. - № 6. - С. 87-101.

6. Наумова Н.Ф. Психологические механизмы свободного выбора // Системные исследования: Методологические проблемы. Ежегодник. - 1983. М.: Наука. - С. 197.

7. Папуш М. Психотехника экзистенциального выбора. М., 2001. - 184 с.

8. Петровский В.А. Метаимпликативная модель экзистенциального выбора // Актуальные проблемы психологии. Самарский регион: Спец. выпуск. Самара: СамГУ, ПИРАО, 2002. - С. 95-102.

(c) Мясникова Зоя Вячеславовна (myasnikovazoya@yandex.ru).

Журнал «Современная наука: актуальные проблемы теории и практики»

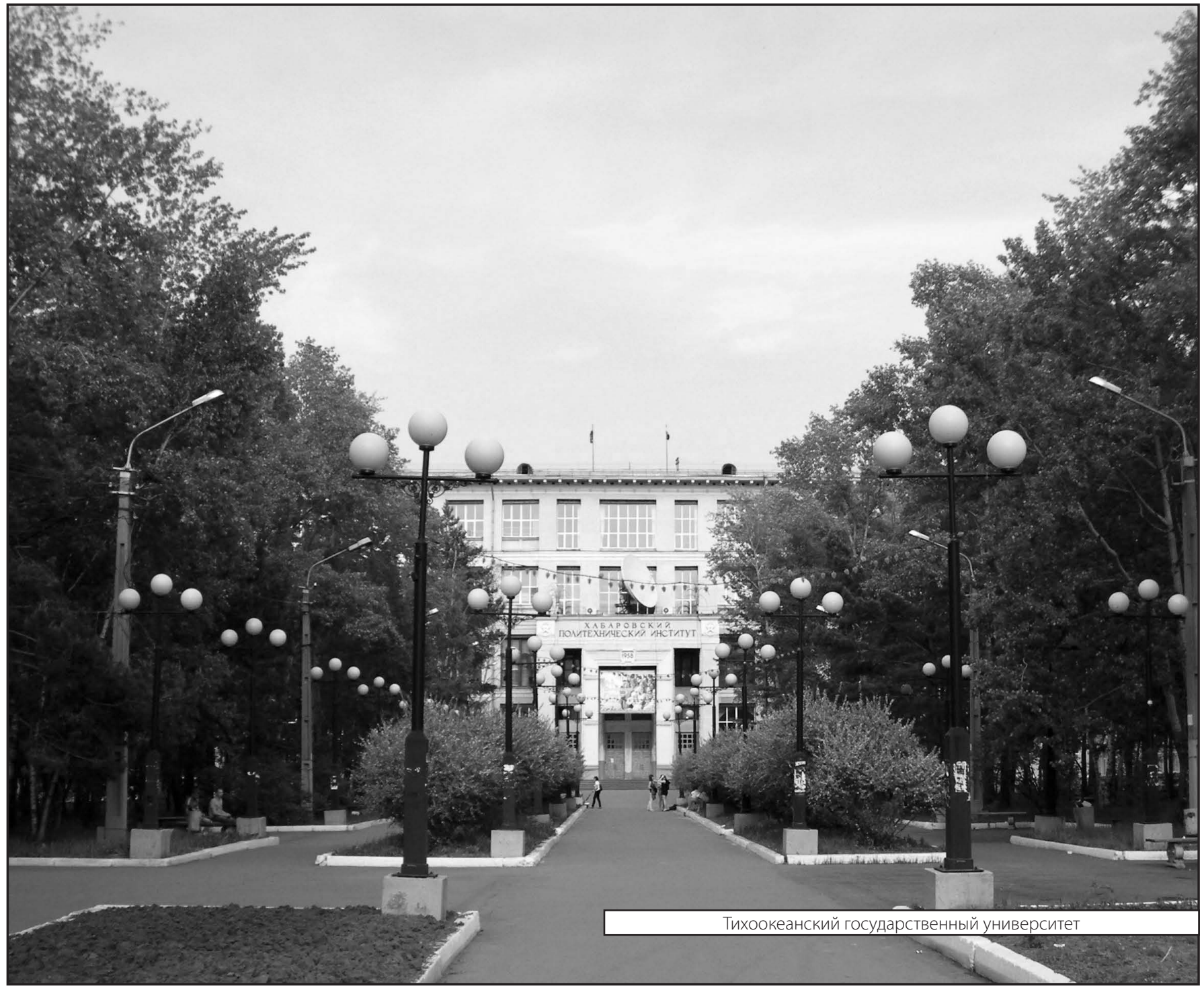

